\title{
Protection by classical and vectored vaccines against endemic velogenic newcastle disease in broiler farms and evaluation of a developed autogenous vaccine against predominant genotype vi
}

\begin{abstract}
This research had three complementary parts, in which the first investigated the broiler's protection on endemic areas with prevalence of v-NDV (genotype VI) by priming day-old broilers on farms with vectored-NDV vaccines and boosting with classical NDV Clone 30 versus priming and boosting on another farms with NDV Clone 30. The second part evaluated protection and immunity by a developed autogenous killed v-NDV in broilers against controlled challenge by genotype VI. The third part included seven broiler flocks on seven different farms located in V-NDV (genotype VI)-endemic area, introducing an additional subcutaneous dose of the developed autogenous vaccine at 6days of age to their program of priming at $\mathrm{d} 1$ with vectored-NDV vaccine and boosting with NDV Clone 30 at d14. The additional autogenous vaccination was delivered to 100 tagged birds embedded in each flock of 22,000 birds. Results of the first part showed protection against genotype VI by NDV clone 30 alone and by combination of vectored-NDV vaccine and Clone 30 of 47.1 and $84.7 \%$, respectively $(\mathrm{P}<0.05)$. Results of the second part showed that priming and boosting with the developed autogenous vaccine conferred a $100 \%$ survival in Eimeria infected and non-infected birds that were challenged with v-NDV compared to $0.0 \%$ survivals in unvaccinated-challenged controls $(\mathrm{P}<0.05)$. The acquired $\mathrm{HI}$ titers to hemaaglutinin and fusion proteins of genotype VI were significantly higher in the vaccinated birds compared to unvaccinated-challenged controls $(\mathrm{P}<0.05)$. The third part showed that the inclusion of an additional one dose of the autogenous NDV vaccine at $6 \mathrm{~d}$ of age improves protection in broilers by $6.5 \%$ compared to flocks deprived of this additional dose $(\mathrm{P}<0.05)$, and higher their $\mathrm{HI}$ titers at $21 \mathrm{~d}$ and $42 \mathrm{~d}$ of age.
\end{abstract}

Keywords: autogenous vaccine. eimeria spp, fusion protein, genotype vi, hemagglutinin protein, immunity, velogenic newcastle disease
Volume 4 Issue 2 - 2017

\author{
E.K Barbour,' M Murtada, ${ }^{2}$ HA Shaib, ${ }^{2} Y$ \\ Abou-Jawdah, ${ }^{2}$ KO Abulnaja, ${ }^{3}$ SS Moselhy, ${ }^{4}$ A \\ lyer, ${ }^{5}$ S Harakeh, ${ }^{6}$ AL Al-Malki, ${ }^{7}$ T Kumosani ${ }^{8}$ \\ 'Department of Agriculture, Faculty of Agricultural and Food \\ Sciences (FAFS), American University of Beirut (AUB), Adjunct \\ to Biochemistry Department, Faculty of Science and Production \\ of Bioproducts for Industrial Applications Research Group, King \\ Abdulaziz University, Saudi Arabia \\ 2Department of Agriculture, Saudi Arabia \\ ${ }^{3}$ Department of Biochemistry, Faculty of Science, Bioactive \\ Natural Products Research Group, King Abdulaziz University, \\ Saudi Arabia \\ ${ }^{4}$ Department of Biochemistry, Faculty of Science, Experimental \\ Biochemistry Unit, King Fahd Medical Research Center, \\ Bioactive Natural Products Research Group, King Abdulaziz \\ University, Saudi Arabia \& Biochemistry Department, Faculty of \\ Science, Ain Shams University, Egypt \\ ${ }^{5}$ Department of Biochemistry, Faculty of Science, Production of \\ Bioproducts for Industrial Applications Research Group,Vitamin \\ D Pharmacogenomics Research Group and Experimental \\ Biochemistry Unit, King Fahd Medical Research Center, King \\ Abdulaziz University, Saudi Arabia \\ 'Production of Bioproducts for Industrial Applications Research \\ Group, Special Infectious Agents Unit, King Fahd Medical \\ Research Center, King Abdulaziz University, Saudi Arabia \\ ${ }^{7}$ Biochemistry Department, Faculty of Science, Bioactive Natural \\ Products Research Group, King Abdulaziz University (KAU), \\ Experimental Biochemistry Unit, King Fahd Medical Research \\ Center, Saudi Arabia \\ ${ }^{8}$ Biochemistry Department, Faculty of Science, Production of \\ Bioproducts for Industrial Applications Research Group and \\ Experimental Biochemistry Unit, King Fahd Medical Research \\ Center, King Abdulaziz University, Saudi Arabia
}

Correspondence: Elie K Barbour, Department of Agriculture, Faculty of Agricultural and Food Sciences, American University of Beirut,Adjunct to Department of Biochemistry, Faculty of Science \& Production of Bioproducts for Industrial Applications Research Group, King Abdulaziz University, Jeddah, P.O. Box: I I-0236, Beirut, Lebanon, Saudi Arabia, Tel 96|3346194, Fax 961 1744460, Email eb01@aub.edu

Received: February 20, 2017 | Published: February 27, 2017

\section{Introduction}

Velogenic Newcastle Disease Virus (v-NDV) belongs to the avian paramyxo virus serotype 1 (APMV-1), with a genome of $16 \mathrm{~kb}$ that encodes for six proteins. ${ }^{1}$ The endemicity of the v-NDV is still reported during the last 5years from many parts of the world, resulting in devastating disease outbreaks in poultry, including breeders, commercial layers, and broilers. ${ }^{2-5}$ Despite the inclusion of different classical and vectored commercial vaccines for the control of different forms of the NDV, the disease is still endemic in poultry of many countries, located in the five continents of our planet, except that of Antarctica. ${ }^{6}$ The presence of a cleavage site motif (112RRQRF117) in the F protein of a NDV strain enables it to be characterized as velogenic, due to its ability to infect systemically. ${ }^{7}$ The hypervariable region of $\mathrm{F}$ protein is also used in dividing the NDV into two classes, under which the genotypes are distributed, and given Roman numbernomenclature. ${ }^{8-10}$ Among the different genotypes, the velogenicneurotropic genotype VI of NDV has been recently reported in outbreaks of poultry from different parts of the world. ${ }^{5,11}$ In spite of all the efforts, introducing new commercial vaccines, aiming at 
protection against a vast range of v-NDV genotypes, still most, if not all of these v-NDV strains are not fully protected against by the available products on the market. ${ }^{12,13}$ This is the main reason behind the regulations in most developed countries to eradicate the poultry that are infected by $\mathrm{v}-\mathrm{NDV},{ }^{14}$ aiming at keeping their poultry sector free of this List a disease. ${ }^{15}$ Unfortunately, and due to the absence of National Poultry Improvement Plans (NPIP) from most developing countries, and the unavailability of compensation to the farmers for eradications, due mostly to poor economy, most of the poultry managers in these countries still introduce vaccines and other biologic enhancers ${ }^{5}$ hoping to protect against the endemic v-NDV outbreaks in their vicinities. The objective of this research is to report the protection against genotype VI by classical NDV Clone 30 and vectored vaccines on different broiler farms that exist in endemic areas of the Middle East region, and to evaluate the degree of protection and immunity against this genotype in broilers that are vaccinated by a developed autogenous killed vaccine and subjected to controlled challenge in isolation, and in broilers flocks exposed to field challenge on seven different farms, located in an endemic area of Genotype VI of v-NDV.

\section{Materials and methods}

The materials and methods for the three parts of this research are shown below:

\section{Part I}

Part I of this research aimed at comparison of broiler survival rates on 10 farms, located in a v-NDV endemic areas, reared under different vaccination programs against Newcastle disease.

Prevalent v-NDV: The prevalent $\mathrm{v}-\mathrm{NDV}$ strains were isolated from broiler outbreaks in an endemic area, at the eastern side of the Mediterranean Sea, located at $34.5440^{\circ} \mathrm{N}, 36.0798^{\circ} \mathrm{E}$. The recovery of the strains was from tracheal swabs, suspended in Transport medium recommended by AAAP, ${ }^{15}$ and inoculated in 100 ul volumes of 10day-old chicken embryonated eggs through the allontoicroute. ${ }^{15}$ The inoculated eggs were incubated at $99.5^{\circ} \mathrm{F}$ for three days, followed by collection of their allontoic fluid, and testing for its Hemagglutination (HA) activity against $1 \%$ of chicken RBC suspension. An allontoic fluid with positive HA activity indicates presence of a propagated virus carrying the hemaaglutinin protein. The confirmation of the v-NDV presence in the tested fluids was done by PCR, using forward and reverse primer sequences targeting the amplification of the viral fusion gene. ${ }^{16}$ The banding of the fusion gene amplicons was performed on Agarose gel, with expectation of its positioning at $254 \mathrm{bp} .{ }^{16}$ The sequencing of the eluted amplicons was performed by using 3500 Avant Genetic Analyzer- ABI PRISM (Applied Biosystems, Hitachi), aiming at revealing the genotype of the $\mathrm{v}-\mathrm{NDV}^{9,10}$ and the uncovering of the structure of its cleavage site motif. The field experimental design in Part I of this research included 10 open-system broiler farms, located in the endemic area of v-NDV of genotype VI $\left(34.5440^{\circ} \mathrm{N}, 36.0798^{\circ} \mathrm{E}\right.$.), with recurrent history of Newcastle disease outbreaks. The average broiler flock size on the 10 farms was 15,000 birds. Five flocks on five respective farms were primed at day-old with same vectored-NDV vaccine (VectormuneR ND, CevaSanteAnimale, 10 Avenue de la Ballastiere, 33500 Libourne, France), receiving subcutaneously $0.2 \mathrm{ml}$ per bird of the thawed vaccine. Boosting of these five flocks was performed by administration of NDV clone 30 vaccine in drinking water at an age of 14days. The other five broiler flocks on another five respective farms, located in the same area, were primed and boosted by administration of ND clone 30 in drinking water at an age of 1 and 14days. The means of cumulative percent survival of healthy marketed broilers at an age of 35-37days were compared statistically between the two treatments by different vaccination programs, using ANOVA and Tukey's test, reporting significant differences at the level of $\mathrm{P}<0.05$.

\section{Part II}

Part II of this research was dedicated to evaluate the protection in broilers by an experimental autogenous killed v-NDV, using the complete antigens of the prevalent strain of V-NDV of genotype VI against a controlled challenge that kills $100 \%$ of non-vaccinated birds. This part of research was accomplished in isolation units.

Autogenous vaccine preparation: The isolated and sequenced prevalent v-NDV of genotype VI was propagated in 10day-old chick embryos, using an inoculum of 100 viral particles/100ul/egg, followed by an incubation for three days, and harvesting of the allotropic fluids from all embryos. Allontoic fluids with HA activity were selected and pooled. The HA titer of the pooled fluid was determined against $1.0 \%$ of chicken RBC suspension. The v-NDV virus in the pooled allontoic fluid was inactivated with $0.3 \%$ formalin at room temperature and a contact time of $2 \mathrm{hrs}$. The inactivation was confirmed by culturing the formalized-pooled allontoic fluid in 10 day-old embryos and proof of non-existing HA activity in their allotropic fluids after an incubation period of 3 days..$^{15}$ An equal volume of the inactivated allontoic fluid and incomplete Freund's adjuvant were emulsified by adding slowly the aqueous phase into the stirring adjuvant, and passing the preformed emulsion through a Colloidal Mill at stator gap setting of 0.002 inches (Greerco, Ohio 45401 USA).

Protection and immunity by autogenous vaccine against v-NDV: The protection and immunity by the autogenous vaccine against controlled v-NDV strain of genotype VI was determined by allocation of three differently treated birds in separate isolation rooms. Each treatment had 10day-old broilers. Birds in the first treatment received the autogenous vaccine subcutaneously in the neck at $1 \mathrm{~d}(0.2 \mathrm{ml} / \mathrm{bird})$ and at $14 \mathrm{~d}(0.5 \mathrm{ml} / \mathrm{bird})$ of age, followed by an intra-muscular challenge in the pectoral muscle at $28 \mathrm{~d}$ of age with $\mathrm{v}-\mathrm{NDV}$ strain $\left(1.2 \times 10^{8 \mathrm{M}} \mathrm{TCID}_{50} / 0.5 \mathrm{ml} / \mathrm{bird}\right)$ and an intra-esophageal immunosuppressive challenge at $21 \mathrm{~d}$ of age with equivalent number of non-attenuated sporulated oocyte of eight Eimeria spp $\left(1 \times 10^{6}\right.$ sporulated oocysts/bird). The introduction of Eimeria spp. challenge in this experiment aimed at stimulating the common situation in the field of continuous exposure of broilers to immunosuppressive organisms of coccidian ${ }^{17}$ that affect the immune responses to vaccination. Birds in the second treatment were deprived of the autogenous v-NDV vaccination, but administered the same two challenges at the same schedule followed in the first treatment. Birds in the third treatment had the same autogenous v-NDV vaccination as that followed in the first treatment, but deprived of both challenges. The survival of the birds, up to market age of 40days, was recorded. In addition, the mean $\mathrm{HI}$ titers of birds in each treatment was determined at $1,14,28$, and $34 \mathrm{~d}$ of age, including in the test the same strain of $\mathrm{v}-\mathrm{NDV}$ as that used in construction of the vaccine. It is worth noting that most mortalities occurred after $34 \mathrm{~d}$ of age. The strength of the viral antigen used in the test was of 4 HA units. ${ }^{15}$ The SDS-PAGE followed by Western Immunoblotting were applied on the sera of all birds ${ }^{18}$ to quantify the mean specific immune responses in the sera collected at different ages $(14,28$, and 34 d) to Trans-blotted fusion protein carried from the SDS-resolving gel to the cellulose membrane of the Western Blotting (Figure 1). The quantification of these intensities was performed by Quantity 1 program (Biorad, 1000 Alfred Nobel Drive Hercules, California 94547, USA). The means of $\mathrm{HI}$ titers and those of quantified intensities at the fusion band were compared statistically among the three treatments by One Way 
ANOVA, followed by Tukey's test. Significant differences among the means were presented at $\mathrm{P}<0.05$.

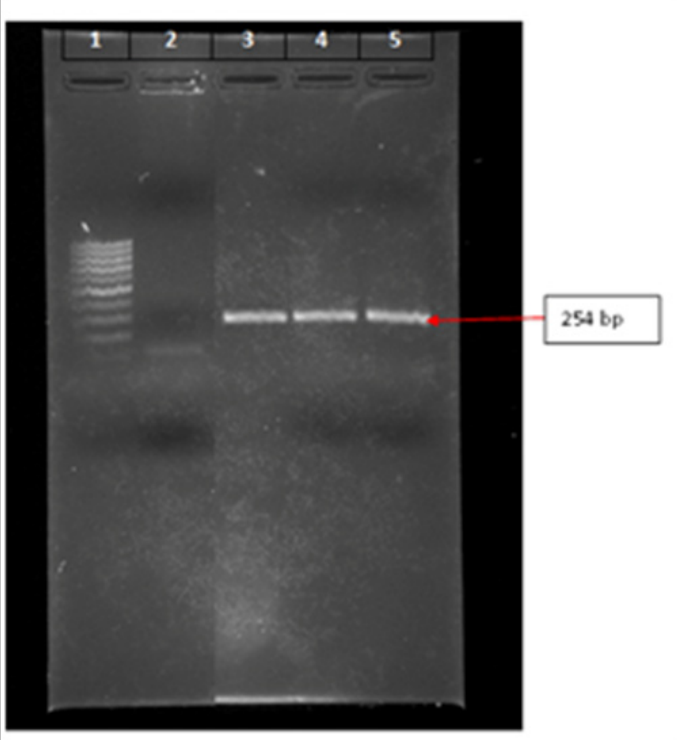

Figure I Representative of fusion genome amplicons of different chicken outbreaks banded on lanes 3, 4, and 5 and located at 254 bp position. Lane has the reference 100 bp ladder, extending from lowest band of highest band of $1000 \mathrm{bp}$, while lane 2 shows a reference genetic fragment of $100 \mathrm{bp}$.

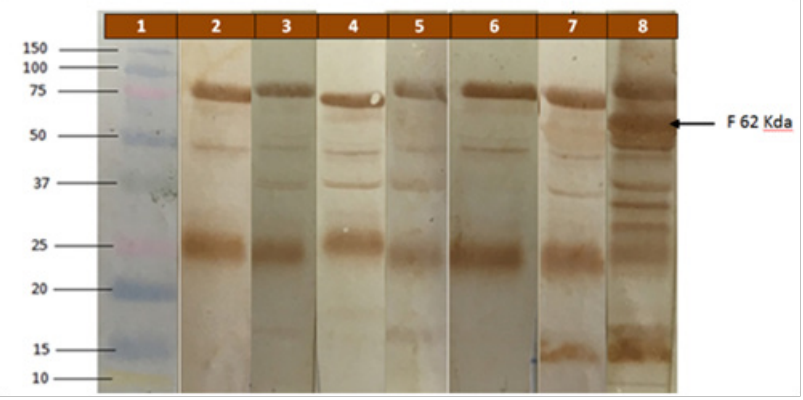

Figure 2 Western Immuno blotting showing the intensities of the reaction between humoral antibodies and the banded fusion protein of genotype $\mathrm{VI}$ of $\mathrm{v}-\mathrm{NDV}$, positioned at $62 \mathrm{Kda}$. Birds of Treatment I received the autogenous vaccine at $\mathrm{dl}$ and $\mathrm{dl} 4$, and challenged with v-NDV at $\mathrm{d} 28$. Birds in Treatment 2 were negative controls, deprived of vaccination and administered challenge by $\mathrm{v}-\mathrm{NDV}$ at $28 \mathrm{~d}$ of age.

a. Lane I: Molecular Ladder (Precision Plus Protein Kaleidoscope Standard, Biorad).

b. Lane 2: Standard negative serum.

c. Lane 3 :Treatment 2 , bird serum collected at $\mathrm{dI} 4$.

d. Lane 4:Treatment 2 , bird serum collected at $\mathrm{d} 28$.

e. Lane 5:Treatment2, bird serum collected at $\mathrm{d} 34$.

f. Lane6:Treatment I, bird serum collected at d/4.

g. Lane 7:Treatment I, bird serum collected at $\mathrm{d} 28$.

h. Lane 8:Treatment I, bird serum collected at d34.

\section{Part III}

Part III of this research is implemented in the field, on seven different broiler farms, located in same endemic area of v-NDV of genotype VI, where Part I of this research was accomplished. This research segment evaluated the introduction of a subcutaneous dose of the experimental autogenous vaccine, constructed in Part II of this work, in addition to a set vaccination program.

Experimental design of part III research: The additional subcutaneous autogenous vaccine administration was delivered in the neck at 6 days of age $(0.2 \mathrm{ml} /$ bird $)$. The delivery was to 100 tagged birds embedded in each of seven major flocks present on seven respective farms. The size of each of the seven major flocks was 22,000 birds. All seven flocks, including the 100 tagged birds/flock, were primed subcutaneously at day 1 with VectormuneR ND and boosted at day 14 with ND Clone 30. The mean percent survivors in the two treatments, embedded versus major flock deprived of an additional vaccination by the autogenous vaccine, were determined on all seven farms, and up to market age of 42 days. In addition, sera of the brachial venous blood of the birds in the two treatments (embedded versus major flocks) was collected at 21 and 42 days of age for quantifying the HI titers against the hemagglutinin protein carried by the v-NDV strain (genotype VI) included in the test at HA units of $4 .{ }^{15}$

\section{Results and Discussion}

\section{Part I}

Genome of prevalent v-NDV in the endemic area: A representative of the banded fusion genome amplicon of the isolated v-NDV strains from economic outbreaks in broilers of the endemic area, located at $34.5440^{\circ} \mathrm{N}, 36.0798^{\circ} \mathrm{E}$ area of the eastern side of the Mediterranean $\mathrm{Sea}$, is shown in Figure 1. The amplicon is positioned at $254 \mathrm{bp}$, a place that is in agreement with that documented for fusion gene of $\mathrm{v}-\mathrm{NDV} .{ }^{16}$ The sequence of the translated amino acids coded by the eluted nucleotides of the fusion gene amplicon aligned with that of genotype VI ( ${ }^{32}$ DGRPLAAAG IVVTGDKAVNVYTSSQ

\section{TGSIIVKLLPNMP} NRTLTTLLTPLGDSIR KC425723.1). In addition, the translated cleavage site motif was identified between positions 112 and $117\left({ }^{112} \mathrm{RRQKR}^{117}\right)$, a cleavage motif that belongs to velogenic nature of Newcastle Disease viruses. ${ }^{14}$

Table I The percent survival of broilers administered vectored vaccine and/ or classical NDV clone 30 in an endemic area with prevalence of velogenic genotype VI

\begin{tabular}{|c|c|c|c|}
\hline Broiler Farm & $\begin{array}{l}\text { Administered } \\
\text { Vaccine }\end{array}$ & $\begin{array}{l}\text { Vaccination } \\
\text { Age (days) }\end{array}$ & \% Survival \\
\hline I & NDV Clone 30 & 1,14 & 47.4 \\
\hline 2 & NDV Clone 30 & $\mathrm{I}, 14$ & 43.7 \\
\hline 3 & NDV Clone 30 & 1,14 & 45.2 \\
\hline 4 & NDV Clone 30 & $\mathrm{I}, 14$ & 51 \\
\hline 5 & NDV Clone 30 & 1,14 & 48.4 \\
\hline Mean & & & $47.1 \mathrm{a}$ \\
\hline \multirow[t]{2}{*}{6} & Vectored Vaccine & I & \\
\hline & NDV Clone 30 & 14 & 80.7 \\
\hline \multirow[t]{2}{*}{7} & Vectored Vaccine & 1 & \\
\hline & NDV Clone 30 & 14 & 85.8 \\
\hline \multirow[t]{2}{*}{8} & Vectored Vaccine & 1 & \\
\hline & NDV Clone 30 & 14 & 87.3 \\
\hline \multirow[t]{2}{*}{9} & Vectored Vaccine & 1 & \\
\hline & NDV Clone 30 & 14 & 86.6 \\
\hline \multirow[t]{2}{*}{10} & Vectored Vaccine & 1 & \\
\hline & NDV Clone 30 & 14 & 83 \\
\hline Mean & & & $84.7 \mathrm{~b}$ \\
\hline SEM & & & 6.3 \\
\hline
\end{tabular}

$a, b$ The two means in the last column followed by different alphabetic superscripts are significantly different at $\mathrm{P}<0.05$. The SEM stands for Standard Error of Means. 
Table 2 Study of the protection by the autogenous vaccinel against genotype $\mathrm{VI}$ of $\mathrm{v}-\mathrm{NDV}$ in presence and absence of 8 Eimeria $^{2}$ spp. Infection

\begin{tabular}{lllll}
\hline Treatments & $\begin{array}{l}\text { Autogenous } \\
\text { Vaccine for } \\
\text { vNDV }\end{array}$ & Challenge & & $\begin{array}{l}\% \\
\text { Survivors }\end{array}$ \\
\hline & Yes & Eimeria spp & v-NDV3 & \\
\hline & No & Yes & Yes & $100.0 \mathrm{a}$ \\
2 & Yes & Yes & Yes & $0.0 \mathrm{~b}$ \\
3 & No & No & $100.0 \mathrm{a}$ \\
\hline
\end{tabular}

'The Autogenous vaccine is a water-in-oil emulsion, in which the aqueous phase contained I28HA units of formalized v-NDV of genotype VI.

${ }^{2}$ The challenge was at $2 \mathrm{I} d$ of age, by equivalent number of Sporulated Oocyst of 8 Eimeria spp (Ix|06sporulated oocysts/bird). The 8 Eimeria spp, were $E$. necatrix, E. acervulina, E. mivati, E. tenella, E. brunetti, E. maxima, E. hagani and $E$ praecox.

${ }^{3}$ The challenge was intramuscular at $28 \mathrm{~d}$ of age, by v-NDV of genotype Vlcontaining I.2xI08TCID50/0.5 $\mathrm{ml} / \mathrm{bird}$. 4Survivors up to market age of 40 days. Most of mortalities in Treatment 2 occurred after 34 days of age.

a,bPercentages in a column followed by different alphabetic superscripts are significantly different $(P<0.05)$.

Comparison of protection by two different vaccination programs: The comparison of the percent survivors of five versus five broiler flocks, subjected respectively to two different vaccination programs, in an endemic area of v-NDV of genotype VI, is presented in Table 1 . The means of \% healthy survivors on five broiler farms subjected to vaccination in drinking water with only the NDV clone 30 at 1 and $14 \mathrm{~d}$ of age versus the other five flocks administered subcutaneously the VectormuneR ND at $1 \mathrm{~d}$ and boosted at $14 \mathrm{~d}$ with NDV clone 30 were $47.1 \%$ and $84.7 \%$, respectively $(\mathrm{P}<0.05)$. This result is in agreement with previous document, reporting the ability of vectored ND vaccines to induce additional specific response to the virulence factor of fusion protein, and not restricted to immune responses to the hemagglutinin (HA) protein of NDV. ${ }^{19,20}$ The humoral immunity produced by NDV clone 30 against HA protein of the virus seems insufficient to provide protection against the virulent v-NDV in this endemic area. Previous reports indicated a failure in correlation of humoral response to HA protein of NDV and protection. ${ }^{20,21}$ Another reports documented the benefit of vectored ND vaccine in its ability to induce humoral immunity to fusion and HA proteins, and cellmediated immunity, two major components of the chicken immune system that are essential in protection against v-NDV. ${ }^{21}$

\section{Part II}

This part dealt with evaluation of protection and immunity induced by the experimental autogenous vaccine in broilers raised in isolation units and subjected to controlled challenge by v-NDV of genotype VI.

Autogenous vaccine: The experimental autogenous inactivated ND vaccine formed a water-in-oil emulsion $(1 / 1 \mathrm{v} / \mathrm{v})$, with average homogeneous micelle diameter of $1 \mathrm{um}$, when refined by the colloidal mill that was set at a Stator Gap of 0.002inches. The HA strength of its aqueous phase was 128 units. This HA strength is within compliance with that recommended in literature, ${ }^{22,23}$ while the micelle fine average diameter was appropriate in preventing the split of its oil and aqueous phases, thus enhancing its stability. ${ }^{24}$

Table 3 Acquired humoral immunity specific to hemaagglutinin I and fusion2 proteins of genotype VI of v-NDV by the developed autogenous vaccine 3 in presence and absence of 8 Eimeria 4 spp. Infection

\begin{tabular}{|c|c|c|c|c|c|c|c|c|c|c|}
\hline \multirow[t]{2}{*}{ Treatment } & \multirow[t]{2}{*}{$\begin{array}{l}\text { Autogenous } \\
\text { Vaccine for } \\
\text { v-NDV }\end{array}$} & \multicolumn{2}{|l|}{ Challenge } & \multicolumn{4}{|c|}{$\begin{array}{l}\text { HITiters at } \\
\text { Age (d) }\end{array}$} & \multicolumn{3}{|c|}{$\begin{array}{l}\text { Intensity of Fusion Band } \\
\times 1000 \text { at age (d) }\end{array}$} \\
\hline & & Eimeria spp & v-NDV5 & I & 14 & 28 & 34 & 14 & 28 & 34 \\
\hline 1 & Yes & Yes & Yes & $\mathrm{I}: 23 \mathrm{a}$ & I:4.4a & $\mathrm{I}: 186 \mathrm{a}$ & $\mathrm{I}: 1997 \mathrm{a}$ & $73.8 \mathrm{a}$ & $107.5 \mathrm{a}$ & 184.Ia \\
\hline 2 & No & Yes & Yes & $1: 23 a$ & I:5.8a & $\mathrm{I}: 0.0 \mathrm{~b}$ & $\mathrm{I}: 0.0 \mathrm{c}$ & $60.7 a$ & $84.7 \mathrm{~b}$ & $84.6 \mathrm{~b}$ \\
\hline 3 & Yes & No & No & $\mathrm{I}: 23 \mathrm{a}$ & $\mathrm{I}: 4.2 \mathrm{a}$ & $\mathrm{I}: 138 \mathrm{a}$ & $\mathrm{I}: \mathrm{I74b}$ & $137.5 \mathrm{a}$ & $157.2 \mathrm{a}$ & $229.9 a$ \\
\hline
\end{tabular}

'The specific humoral immunity to hemaagglutin in protein on v-NDV was measured by Hemaagglutination-Inhibition test.

${ }^{2}$ The specific humoral immunity to fusion protein on v-NDV was measured by the intensity of its band on cellulose membrane of the Western Immunoblotting. ${ }^{3}$ The Autogenous vaccine is a water-in-oil emulsion, in which the aqueous phase contained I28HA units of formalized v-NDV of genotype VI.

${ }^{4}$ The challenge was at $2 \mathrm{I} \mathrm{d}$ of age, by equivalent number of sporulated Oocyst of 8 Eimeriaspp (IxI06sporulated oocysts /spp.). The 8 Eimeria spp were E. necatrix, E. acervulina, E. mivati, E. tenella, E. brunetti, E. maxima, E. hagani and E. praecox.

${ }^{5}$ The challenge was intramuscular at $28 \mathrm{~d}$ of age, by v-NDV of genotype VI containing I.2xI08TCID50/0.5 ml/bird.

a-c Values in a column with different alphabet superscripts are significantly different $(P<0.05)$

Protection and immunity by the autogenous ND vaccine: The broiler survivor rate in the first treatment was $100 \%$, receiving autogenous vaccine at $\mathrm{d} 1$ and $\mathrm{d} 14$ and challenged with $\mathrm{v}-\mathrm{NDV}$ at $\mathrm{d} 28$ and with eight Eimeria spp at d21 (Table 2). On the contrary, the survival in the positive control birds of the second treatment, that were deprived of the autogenous vaccine and receiving the same challenge as that of first treatment, was null. The negative control birds of the third treatment, that were vaccinated and deprived of both challenges, had a $100 \%$ survival. The significant survival of vaccinated and challenged birds of first treatment is in agreement with other workers that documented a full protection against devastating diseases in poultry by autogenous killed vaccines, incorporating in it the homologous strain that is used in the challenge. ${ }^{25,26}$ Researchers showed also the high efficacy of autogenous killed ND vaccine in protection against homologous v-NDV. ${ }^{27}$ It is worth noting that Eimeriaspp. infection is prevalent in chicken, causing suppression of acquired immunity to vaccines, and more specifically to ND vaccines. ${ }^{28}$ In spite of the known fact about the suppression of immunity by Eimeria spp., still the autogenous vaccine was highly protective against a homologous challenge with v-NDV of genotype VI. In addition, the survival of all birds in the third treatment that received the vaccine and deprived of both challenges indicates the safety of the administered vaccine. Actually, the use of killed vaccines in poultry husbandry is favored, since it is devoid of living organisms that might cause a vaccine reaction or even significant loss in production under certain stressful situations. ${ }^{29,30}$ Regarding the acquired immunity in birds of the three treatments (Table 3), the autogenous vaccine administered at 1 and $14 \mathrm{~d}$ of age in birds of first and third treatments was able to induce significant high $\mathrm{HI}$ titers and specific immunity to fusion protein of $\mathrm{v}-\mathrm{NDV}$ at $28 \mathrm{~d}$ and $34 \mathrm{~d}$ of age compared to birds deprived of the vaccine in the second treatment $(\mathrm{P}<0.05)$. The higher $\mathrm{HI}$ titers specific to Hemagglutinin protein and the higher specific antibodies to fusion 
protein are most likely the reason behind having a full protection by the autogenous vaccine in birds of Treatment 1 . Figure 2 is selected as a demo to show differences in intensity of specific antibodies reacting to banded fusion protein on cellulose membranes as a result of acquired immunity to autogenous vaccine and to controlled challenge by v-NDV of Genotype IIV. Actually, previous workers were able to relate the high protection in chicken against $\mathrm{v}-\mathrm{NDV}$ to the significant immune responses to hemagglutinin and to fusion proteins. ${ }^{31,32}$

Table 4 Evaluation of the developed autogenous vaccine' administered to embedded birds ${ }^{2}$ of six respective flocks ${ }^{3}$ located on 6 farms in an area with recurrent outbreaks by genotype VI of v-NDV

\begin{tabular}{|c|c|c|c|c|c|c|}
\hline \multirow[t]{3}{*}{ Flocks } & \multirow{2}{*}{\multicolumn{2}{|c|}{$\%$ Survivors }} & \multicolumn{4}{|c|}{ Mean $\mathrm{HI}$ titers at different ages in days (d) } \\
\hline & & & \multicolumn{2}{|c|}{$21 \mathrm{~d}$} & \multicolumn{2}{|l|}{$42 \mathrm{~d}$} \\
\hline & Major Flock & Embedded Birds & Major Flock & Embedded Birds & Major Flock & Embedded Birds \\
\hline I & 87.7 & 93 & 2 & 2.2 & 6.5 & 9.2 \\
\hline 2 & 85.8 & 92 & 9.8 & 42.4 & - & - \\
\hline 3 & 85.2 & 88 & 8.8 & 15.6 & - & - \\
\hline 4 & - & - & 7 & 6.4 & 22.4 & 32 \\
\hline 6 & 86.3 & 93 & 0.8 & 2.6 & 13.2 & 18.8 \\
\hline 7 & 84.2 & 93 & 0.8 & 3.2 & 20.8 & 38.4 \\
\hline Means & $84.5 \mathrm{a}$ & $91.0 \mathrm{~b}$ & $4.6 \mathrm{a}$ & II.5a & $13.5 \mathrm{a}$ & $22.6 a$ \\
\hline
\end{tabular}

'The Autogenous vaccine is a water-in-oil emulsion, in which the aqueous phase contained I 28 HA units of formalized v-NDV of genotype VI.

${ }^{2}$ One hundred birds were randomly selected and tagged and embedded in each of the major 6 flocks. Each of these 100 s were administered an dditional subcutaneous injection of $0.2 \mathrm{ml}$ of the developed autogenous vaccine at six days of age. Both the birds in the major flocks and the 100 birds embedded in each flock received the same feed and water, same vaccination program, and living in identical environment

${ }^{3}$ The total number of each major flock plus the 100 embedded birds in each was 22,000 .

a,bEach compared two means in the last row of this table, located under the same subtitle, and followed by different alphabet superscripts, are significantly different $(\mathrm{P}<0.05)$

\section{Conclusion}

In conclusion, part I of this research was able to observe the benefit of priming with vectored ND vaccine at $\mathrm{d} 1$ and boosting with ND Clone 30 compared to priming and boosting by ND Clone 30 on farms present in an endemic area of v-NDV of genotype VI. In addition, part II uncovered the high protection by killed autogenous ND vaccine against a controlled bivalent challenge with homologous v-NDV of genotype VI and immunosuppressive Eimeria spp. Moreover, part III showed the advantage in protection and immunity of broilers raised in an endemic area of $\mathrm{v}-\mathrm{NDV}$ by introducing an additional administration of autogenous ND vaccine at 6days of age to established vaccination program, involving priming at $\mathrm{d} 1$ with vectored ND vaccine and boosting at $\mathrm{d} 14$ with ND Clone 30 . It is recommended in the future to investigate the protection and immunity by priming and boosting with the developed autogenous v-NDV vaccine alone in broilers present in such endemic areas.

\section{Acknowledgments}

None.

\section{Conflicts of interest}

Author declares there are no conflicts of interest.

\section{Funding}

None.

\section{References}

1. ICTV 9th Report. International Committee on Taxonomy of Viruses Netherlands. 2009.

2. Ababneh MM, Dalab AE, Alsaad SR, et al. Molecular characterization of a recent Newcastle disease virus outbreak in Jordan. Res Vet Sci 2021;93(3):1512-1514.
3. Radwan MM, Darwish SF, El Sabagh, et al. Isolation and molecular characterization of Newcastle disease virus genotypes II and VIId in Egypt between 2011 and 2012. Virus Genes. 2013;47(2):311-316.

4. Umali DV, Ito H, Shirota K, et al. Atypicalvelogenic Newcastle disease in a commercial layer flock in Japan. Poult Sci . 2015;94(5):890-897.

5. Barbour EK, Shaib H, Azhar E, et al. Modulation by essential oil of vaccine response and production improvement in chicken challenged with velogenic Newcastle disease virus. J Appl Microbiol. $2013 ; 115(6): 1278-1286$

6. Alexander DJ, Senne DA. Newcastle disease, other avian paramyxoviruses, and pneumovirus infections. Diseases of Poultry (12th edn), Blackwell Publishing, USA. 2008. p.75-98.

7. Gravel KA, Morrison TG. Interacting domains of the $\mathrm{HN}$ and $\mathrm{F}$ proteins of Newcastle disease virus. J Virol . 2003;77(20):11040-11049.

8. Aldous EW, Mynn JK, Banks J, et al. A molecular epidemiological study of avian paramyxovirus type 1 (Newcastle disease virus) isolates by phylogenetic analysis of a partial nucleotide sequence of the fusion protein gene. Avian Pathol. 2003;32(3):237-255.

9. Kim LM, King DJ, Curry PE, et al. Phylogenetic diversity among lowvirulence Newcastle disease viruses from waterfowl and shorebirds and comparison of genotype distributions to those of poultry-origin isolates. J Virol . 2007;81(22):12641-12653.

10. Courtney SC, Susta L, Gomez D, et al. Highly divergent virulent isolates of Newcastle disease virus from the Dominican Republic are members of a new genotype that may have evolved unnoticed for over 2 decades. $J$ Clin Microbiol. 2013;51(2):508-517.

11. Munir M, Shabbir MZ, Yaqub T, et al. Complete genome sequence of a velogenic neurotropic avian paramyxovirus 1 isolated from peacocks (Pavocristatus) in a wildlife park in Pakistan. $J$ Virol. 2012;86(23):13113-13114.

12. Afonso CL, Miller PJ. Newcastle disease: progress and gaps in the development of vaccines and diagnostic tools. Dev Biol (Basel). 2013;135:95-106. 
13. Roohani K, Tan SW, Yeap SK, et al. Characterisation of genotype VII Newcastle disease virus (NDV) isolated from NDV vaccinated chickens, and the efficacy of LaSota and recombinant genotype VII vaccines against challenge with velogenic NDV. $J$ Vet Sci . 2015;16(4):447-457.

14. Newcastle disease (infection with Newcastle disease virus). World Organization for Animal Health (OIE). OIE Terrestrial Manual, USA. 2012. p.1-20.

15. Dufour Zavala L. A laboratory manual for the isolation, identification, and characterization of avian pathogens. American Association of Avian Pathologists, USA. 2008. p.1-249.

16. Viljoen GJ, Nel LH, Crowther JR. Disease Diagnosis Using PCR Specific Procedures for Important Veterinary Pathogens. Molecular Diagnostic PCR Handbook, Springer, USA. 2005. p.120-201.

17. Barbour EK, Bragg RR, Karrouf G, et al. Control of eight predominant Eimeria spp. involved in economic coccidiosis of broiler chicken by a chemically characterized essential oil. $J$ Appl Microbiol. 2015;118(3):583-591.

18. Barbour EK, Halawi HM, Shaib HA, et al. Impact of competitive nonprotective antigens in a booster killed vaccine on seroconversions to protective antigens of Newcastle disease virus in chickens. Vet Ital. 2011;47(4):461-468.

19. Reynolds DL, Maraqa AD. Protective immunity against Newcastle disease: the role of antibodies specific to Newcastle disease virus polypeptides. Avian Dis. 2000;44(1):138-144.

20. Kumar S, Nayak B, Collins PL, et al. Evaluation of the Newcastle disease virus $\mathrm{F}$ and $\mathrm{HN}$ proteins in protective immunity by using a recombinant avian paramyxovirus type 3 vector in chickens. $J$ Virol. 2011;85(13):6521-6534.

21. Gowrakkal M, Vijayarani K, Kumanan K, et al. Determination of immune potentials of recombinant fusion and recombinant haemagglutininneuraminidase antigens of Newcastle Disease virus (NDV). Int $J$ CurrMicrobiol App Sci. 2015;4(1):575-588.

22. Kapczynski DR, Afonso CL, Miller PJ. Immune responses of poultry to Newcastle disease virus. Dev Comp Immunol . 2013;41(3):447-453.

23. Allan WH, Lancaster JE, Toth B. Newcastle disease vaccines, their production and use. Food and Agriculture Organization of the United Nations, USA. 1978. p.1-163.

24. BinksBP, Whitby CP. Silica particlestabilized emulsions of silicone oil and water: aspects of emulsification. Langmuir. 2004;20(4):1130-1137.
25. Ronco T, Stegger M, Andersen PS, et al. Draft genome sequences of two avian pathogenic Escherichia coli strains of clinical importance, E44 and E51. Genome Announc. 2016;4(4):e00768-e00816.

26. GharaibehS, Amareen S. Vaccine Efficacy Against a New Avian Influenza (H9N2) Field Isolate from the Middle East (Serology and Challenge Studies). Avian Dis. 2015;59(4):508-511.

27. Zhu J, Hu S, Xu H, et al. Characterization of virulent Newcastle disease viruses from vaccinated chicken flocks in Eastern China. BMC Vet Res. 2016;12(1):113.

28. Akhtar M, Awais MM, Anwar MI, et al. The effect of infection with mixed Eimeria species on hematology and immune responses following Newcastle disease and infectious bursal disease booster vaccination in broilers. Vet Q. 2015;35(1):21-26.

29. Marangon S, Busani L. The use of vaccination in poultry production. Revue Scientifiqueet Technique-Office International des Epizooties. 2007;26(1):265-274.

30. Jeurissen SH, Boonstra-Blom AG, Al Garib SO,et al. Defence mechanisms against viral infection in poultry: a review. Vet $Q$. 2000;22(4):204-208.

31. Firouzamandi M, Moeini H, Hosseini D, et al. Improved immunogenicity of Newcastle disease virus inactivated vaccine following DNA vaccination using Newcastle disease virus hemagglutinin neuraminidase and fusion protein genes. J Vet Sci. 2016;17(1):21-26.

32. Loke CF, Omar AR, Raha AR, et al. Improved protection from velogenic Newcastle disease virus challenge following multiple immunizations with plasmid DNA encoding for $\mathrm{F}$ and $\mathrm{HN}$ genes. Vet Immunol Immunopathol. 2005;106(3-4):259-267.

33. Park MS, Steel J, García-Sastre A, et al. Engineered viral vaccine constructs with dual specificity: avian influenza and Newcastle disease. Proc Natl Acad Sci US. 2006;103(21):8203-8208.

34. Esaki M, Godoy A, Rosenberger JK, et al. Protection and antibody response caused by turkey herpesvirus vector Newcastle disease vaccine. Avian Dis . 2013;57(4):750-755.

35. Kim SH, Wanasen N, Paldurai A, et al. Newcastle disease virus fusion protein is the major contributor to protective immunity of genotypematched vaccine. PLoS One. 2013;8(8):e74022.

36. Taylor J, Edbauer C, Rey Senelonge A, et al. Newcastle disease virus fusion protein expressed in a fowlpox virus recombinant confers protection in chickens. $J$ Virol. 1990;64(4):1441-1450. 